\title{
Current and future trends in educational computing: Implications for training language teachers
}

\section{Jannie Botha}

In the first part of this paper an overview is given of the current state of educational technology as well as some future trends in this rapidly developing field. The focus is on developments with regard to hardware and sof tware. It is pointed out that a clear distinction between hardware and software is not always possible. Specific reference is made to a Hypertext programme and the promises it holds for the future.

In the second part of the paper specific guidelines for training teachers in computerassisted language instruction (CALI) are given. This is done against the background given in the first part of the paper. Guidelines are proposed for the training of language teachers.

In die eerste gedeelte van hierdie artikel word' $n$ oorsig gegee van die huidige stand van opvoedkundige tegnologie en ook sommige toekomsneigings op hierdie snelontwikkelende gebied. Die fokus val op ontwikkelings ten opsigte van apparatuur en programmatuur. Daar word aangedui dat ' $n$ duidelike onderskeid tussen apparatuur en programmatuur nie altyd moontlik is nie. Daar word spesifiek verwys na' nhiperteksprogramen die moontlikhede wat dit vir die toekoms inhou.

In die tweede gedeelte van die artikel word spesifieke riglyne vir die opleiding van rekenaargesteunde taalonderrigonderwysers (RGTO) gegee. Dit word gedoen teen die agtergrond wat in die eerste gedeelte van die artikel gegee is. Riglyne vir die opleiding van taalonderwysers word voorgestel.

\section{Overview}

The aim of this paper is to give an overview of the current and future trends in educational computing. In order to do this, the focus will be on developments with regard to hardware, software, and peripheral equipment. It should be pointed out that it is not possible to make a clear distinction in every instance.

Furthermore, this emerging technology has implications for the training of language teachers. The second part of this paper will therefore deal with the training of language teachers for computer-assisted language instruction (CALI). 


\section{Hardware}

We have come a long way in educational computing since the middle of the sixties when a big main frame computer had only $64 \mathrm{kB}$ of memory but was regarded as a powerful computer!

The advances in the field of hardware have hit us at such a devastating rate that it is rather difficult to keep abreast of what is happening in this area. One thing is certain: we cannot blame the existing hardware for not being able to do what we want to do. With microcomputers operating at $20-30 \mathrm{mHz}$, processing speed is no longer a problem.

Apart from the fast CPU's which are now part of many microcomputers, one should also look at the memory capacity. For quite a long time $64 \mathrm{kB}$ on the motherboard was the limit; later expansions of the motherboard allowed $256 \mathrm{kB}$ (as late as 1984 when the IBM ${ }^{1}$ PC was regarded as the ultimate machine). Very soon the so-called IBM AT's started to break this barrier by including $512 \mathrm{kB}$ on the motherboard. However, this configuration was not taken up by other manufacturers with the result that $640 \mathrm{kB}$ became the standard as far as memory was concerned. For a while this barrier was adhered to because the Disk Operating System (known as DOS) could not go beyond 640kB.

At present the DOS can still handle only $640 \mathrm{kB}$ but other collaborating software makes it possible to install extra memory cards, upgrading the memory to $2,5 \mathrm{mB}$, or even higher. It is, of course, very good to have extra memory available in a microcomputer given the prerequisite that the programs (software) one uses can make use of the extended or expanded ${ }^{2}$ memory. The majority of programmes still do not go beyond $640 \mathrm{kB}$.

Apart from the considerations with regard to processing speed and memory, we should also consider the improved storage facilities now available. For a very long time $360 \mathrm{kB}$ floppy disc drives were the standard. The introduction of hard or fixed discs improved this situation in the sense that $20 \mathrm{mB}$ drives became available. Very soon this barrier was exceeded and we now have fixed discs with capacities ranging up to $600 \mathrm{mB}$. This does not include other peripheral devices such as CD-ROM.

The hardware has developed to such a degree that electronic storage devices are slowly penetrating the market. Slowly in this regard merely reflects on the cost-effectives of such devices and not necessarily on the quality of the devices. Some of these devices are: CDROM (Compact Disc Read Only Memory),WORM (Write Once Read Many times), CDI (Compact Disc Interactive), and DVI (Digital Video Interactive). Although these devices could be classified as peripheral at this stage, it is merely a matter of time before they are built into microcomputers. It is therefore necessary to combine our discussion of hardware with a discussion of peripherals at this stage.

If we look ahead, and focus on the future of CD-ROM, some very interesting information is put forward (Robertson, 1988:53 ff). It seems as if this technology will first have to become part of the home entertainment scene before prices will drop to such an extent that it could be considered for educational purposes. A similar case in point is the well-known VCR (video cassette recorder). When we refer to CD-ROM for home entertainment we would like to see this type of entertainment to be as sophisticated as today's television 
programmes with regard to look and sound. There is no doubt that the technology for this is in place and that it will only take a few irresistible applications to start the ball rolling.

In the video market the lack of standards created all sorts of problems, even in the case of video discs where the confusion seems to be even greater. With regard to CD-ROM a standard for logical file structures have recently been agreed on and this should make life easier for educational institutions. Transportability of video material is, of course, important in a low-budget context - something we are all thoroughly familiar with!

The storage capacity of CD-ROM is something which is beyond our grasp. It can store $600 \mathrm{mB}$ of data which is equivalent of 150,000 single-spaced typewritten pages, or enough pages to fill two filing cabinets. With the latest compression techniques even more data can be stored on these discs. And a computer can retrieve any piece of data on such a disc within about one second.

More important is the price of CD-ROM discs. Expectations are that the price could drop to $\$ 10$ per disc - much cheaper than microfiche with the same amount of data but costing $\$ 150$. The price of a CD-ROM drive is $\$ 800$ at the moment but it is expected to drop as low as $\$ 200$ (the price of a compact disc player).

One of the major benefits for education with regard to CD-ROM is that discs are filled with maps, medical and financial information. In some cases encyclopedias (e.g. Grollier's 21 volumes) will fit on these discs. Microsoft's Bookshelf is already available on CD-ROM discs. With the increasing number of reference works becoming available on laser disc, one could see a time when it will be cheaper to buy the discs than sets of books because the discs can be updated more frequently. Because the data on CD-ROM discs is digitized, drawings or text can be moved into computer graphics applications.

While CD-ROM drives now require a computer for data access, there is no reason why the computer chips and operating system could not be built into these drives. The resulting player could use a television set for a monitor and some pointing device. In this way a CDROM drive could become a computer in its own right.

Looking further towards more of a household product, there is the CD-I (Compact Disc Interactive). Due to the fact that it is a household product, it will be a stand-alone computer rather than a computer peripheral. With the latest data compression techniques one can now fit 72 minutes of video material onto a CD-I. Along the same line there is DVI (Digital Video Interactive). Because this equipment is not tied to any particular operating system or hardware, there is the possibility that it could use the MS-DOS operating system as well as Intel chips.

What about challenges to come? CD-ROM could perhaps be relegated to a desktop where it will compete with WORM drives which are, despite their price, much faster than CD-ROM. The latter could even be replaced by WORM drives. This means that one should not invest all your money in $\mathrm{CD}-\mathrm{ROM}$ !

The big disadvantage of all these devices are that they contain data which cannot be changed. However, in the meantime Tandem announced that they are working on an erasable compact disc. It is 18 months away, and the price should be in the region of $\$ 500$. At the TESOL Convention in 1987 it was announced that $3 \mathrm{M}$ was working on a similar project and that it would be available by the end of 1987 . So far, I have not seen any literature about 3M's erasable compact disc. These announcements could signal the death of CD-ROM as the basis for interactive media. 


\section{Software}

If one looks at software, we still have to cope with a rather unfriendly MS-DOS. It may be a while before we can afford computers that will run under the new OS $/ 2$ operating system. It is a fact that a user-friendly operating system could make life much easier for novices starting with computer-assisted instruction.

By far the most important software development for educational purposes is hypertext, a term coined by Ted Nelson. Although many people see the only application for hypertext to be an enhancement or a replacement of desktop publishing, there are also educational applications.

What is hypertext? According to Ted Nelson it is a method of accessing associative trails of information (Robertson, 1988:54). Hypertext expands on the notion of a relational data structure to provide a seamless environment in which the distinction between readers and authors is blurred - readers can add new information and new connections (Robertson, 1988:54).

An example of hypermedia or hypertext (Healy, 1983:3) should make this point clear.

Imagine a student reading a text and he reaches a difficult word. Rather than putting the text down to thumb through a dictionary, he gets an instant definition - in the target language or in his native language, complete with graphics, if necessary. Looking at a footnote, can instantly connect the student to a summary of the referenced article. Another text to be read aloud on an audio tape, or a student can watch a video recording for more information.

All these options are available with Hypermedia. John Underwood's Zarabanda Notebook (ZN) is a prototype of a hypermedia programme designed to accompany an off-the-shelf video disc. $\mathrm{ZN}$ is a series of cards displayed on the computer screen. These cards allow students a preview option, such as reading a story, seeing the cast of characters and looking at a map. The student can view the video sequentially or view the story-line on cards.

It must be emphasized that hypermedia is not a replacement for teacher-student interaction. It allows for a far richer language experience than reading or viewing a video alone. In hypermedia a larger amount of language and linguistic data can be made available to students. The ultimate aim is to help students come out of a session with enriched learning experiences.

Software which is now becoming readily available will place greater demands on hardware as such. It is, for example, preferable that a hypertext program such as GUIDE should run on a computer with a hard disc, an $80286 \mathrm{CPU}$, and with at least $1 \mathrm{mB}$ of internal memory (RAM). Under these conditions it will be fairly easy to develop programs for educational purposes.

After all this has been said, one may ask: What does the ideal teaching machine look like? As Yazdani (1986:146-149) pointed out, the past 30 years of computer-assisted (language) leaming have brought improvements in the richness of feedback and the degree of individualization. However, they are all basically a way of learning by being told. Yazdani 
maintains that despite the advances in CALI it suffers from a behaviourist and reinforcement theory of learning. It is therefore necessary to look at intelligent tutoring systems and experts systems as possible improvements beyond the above-mentioned ways of learning.

Intelligent tutoring systems were probably the first examples of a radically new approach to educational computing. While CALI used a drill and practice approach, intelligent tutoring systems aimed at being diagnostic. For example, the following incorrect subtraction and addition will not result in a simple "wrong" message on the screen, but will lead to a correct diagnosis of the student's error in forgetting to borrow or to carry over:

$170 \quad 33$

$-93+179$

$\overline{187} \overline{102}$

Intelligent tutoring systems try to give a clear indication of knowledge in a rather narrow domain. One such system, DEBUGGY, performs as well as, or even better, than human teachers in a diagnosis of misconceptions of students when performing subtraction. A refinement of this program by Yazdani and Attisha was made to include multiplication, which is by nature more complex than subtraction (Attisha and Yazdani 1984).

The concept behind an expert system is that it should learn from the student. It need not be programmed in advance to accept all the possibilities in a module of knowledge. These systems can be made to understand enough language to understand what a student is trying to say. I do not have to remind you about the complexity of language. You can therefore understand really how intelligent a tutoring system must be to handle this type of interaction!

An extension of an expert system could be a teaching machine. Work in this area is sufficiently advanced to incorporate techniques into the programme which will enable it to learn about the domain it is teaching. It should be pointed out that this type of sophistication requires computational power well beyond the financial resources of education in South Africa.

Instant feedback has been one of the twins of computer-assisted learning (CAL) for a very long time. Artificial Intelligence now seems to provide the possibility that this feedback could be enriched to such an extent that it will be meaningful to the user. Because human intelligence is also developing at a rapid pace, one should not expect to find that a computer programme's Artificial Intelligence will easily catch up with human intelligence.

\section{Peripheral equipment}

Up to now educationists in South Africa have been forced (by budget restrictions) to think in terms of dot matrix printers. Only rarely will people think in terms of more sophisticated printers, such as an ink-jet printer or a laser printer, not to mention colour printers - which will include laser colour printers within the next 18 months to 2 years. In the beginning laser colour printers will be very expensive (as has been the case with most peripheral equipment).

If one looks at possibilities to enrich the computer-assisted learning environment, then surely interactive video should present itself. Despite the limitations with regard to 
computer-controlled VCR's, viz. linear presentation of material, slow frame-finding, crosstalk, etc., these machines can, with clever editing, be very useful in the classroom. One could regard clever editing for educational purposes as something that belongs to the future because you need sophisticated equipment for this. In other words, most aspects of interactive video should be regarded as part of future developments in educational computing.

There is a wonderful new aspect of interactive video, viz. the video disc. Even on this exciting road there are still many obstacles. One problem is the incompatibility of video disc players. This means that discs prepared for a Pioneer video disc player, will not be suitable for a National player. This is really nothing new if we think about the difference between BETA and VHS video formats. In the case of video discs this is a serious problem because of the investment in the equipment - close to R7000,00 without the latest surcharges! As is the case with different video tape standards, one has to choose between NTSC (American) and PAL (European) formats, ignoring France's SECAM for the moment.

The price of video discs are determined by the type of player used. In the case of NTSC, a non-master disc (one-off) can be printed for a fraction of the cost of a PAL disc. In the case of the latter format, a non-master disc is not available. However, if one opted for the NTSC format then all video tapes wil have to be converted from PAL to NTSC at a substantial cost before video discs can be produced. It may still be a very long time before manufacturers agree on a common standard for video discs, but perhaps not so long before the mastering of discs in South Africa becomes a reality.

As far as INTERACTIVE SOUND is concerned, the picture is much brighter. The possibility to digitize sound and store it on a hard disc opens many new doors for language and other related subjects, e.g. ear-training as part of music teaching. Some of the authoring systems used in South Africa (e.g. QUEST) already offer the possibility to read sound from a hard disc. This is a very exciting development in CALI.

The next exciting step in foreign language teaching is about 12-18 months away. At that stage it should be possible for the student's vocal responses to be recorded by the computer programme, stored on a hard disc; then the master's as well as the student's voices can be played back to the student. A programme that will handle this function has already been developed at the University of Stellenbosch. Something which is more difficult but not beyond the computer's capability, is that the computer will compare the student's response to the master's and present a visual image of the differences on the screen. In the beginning this will be a rather crude comparison but there is no doubt that such a comparison can be refined and that students can benefit from this type of feedback.

If one looks at ALTERNATIVE INPUT devices (i.e alternatives to the standard QWERTY keyboard), some interesting possibilities are already available.

One important alternative input device that one should not overlook, and which is becoming increasingly popular, is the mouse device. More and more programs make provision for mouse input. One of the reasons is to avoid having to use the QWERTY keyboard which is not that easy to learn. A big advantage of the mouse is that it gives the impression of pointing at the screen. Some people maintain that this is one way of making educational technology more user-friendly.

Microwriter (Leonard 1985:119) has been on the market for some years now. It did not receive the attention it deserves because of its high price. The latest version, known as 
Quinkey, has six keys which can be used in different combinations to produce text. These combinations can be leamed very quickly (in less than two hours). They allow each user to have his own personal keyboard while the standard keyboard remains available. The main advantage of this device is that it can be used for touch-typing by people who find it hard to master the QWERTY keyboard.

The concept keyboard (described by Leonard 1985:118, and others) is a touch-sensitive pad and can be regarded as the chameleon of alternative input devices. It allows for rearranging of the keys of a QWERTY keyboard so that simple text entries can be made by non-typists. The main drawback it suffers from at the moment is the lack of software which will make it useable in an educational setting. (An example of a concept keyboard can be seen at any of the instant cash machines.)

The ultimate in alternative input devices is voice recognition which enables the computer to understand spoken commands (Jones and Fortescue 1987:134). An example of this device is used in the Alvey Project in Edinburgh. It comprises a voice-driven word-processing programme which can recognise $90 \%$ of instructions correctly out of a vocabulary of 500 words. However, it could still be a while before such a facility is available on microcomputers.

\section{Teachers' training}

After having considered all these wonderful, challenging devices, one could expect to find at least two reactions among listeners/readers:

* Well, if this is the scenario, it is back to the chalk-and-talk approach for me, thank you!

* Wonderful news! Where and how do I learn more about all these possibilities?

The remaining part of this paper deals with ways to satisfy the second reaction, viz. teachers' training, as well as the content of such a training programme.

One could start by looking at different ways of training teachers in computer-assisted language instruction. In this paper three possible ways of training will be discussed (Curtin and Shinall, 1987:255 ff).

5.1 Computer courses: In most cases teachers will learn about computers and other technological devices while they are still being trained as teachers. Apart from this basic "machine knowledge" they should also receive information about the instructional applications of computers and related technology.

5.2 Applied computer courses: In these courses teachers should get information about the instructional possibilities of computers as 
well as a taste of computer programming. They should come to realize that computers can be useful tools for teachers and students. In other words, they should obtain a vision of what computers could do to support their teaching activities.

5.3 In-service training: This category will include workshops, conferences and seminars. The time spent in this type of training could vary from 4 to 40 hours. To some extent the success rate depends on the time spent in the training but it is impossible to make a direct link between time and success in this case. It will differ from teacher to teacher.

5.4 Technical knowledge is a useful part of teachers' training in so far as teachers often want to feel that they are in control of the equipment they use. This type of knowledge does not entail that a teacher should be able to take a computer apart and reassemble it when something goes wrong. Unless he is very much mechanically minded, this may be the end of his CALI career!

According to Higgins and Johns (1984:100) teachers can become involved with computers at three different levels. They may evaluate computers and programmes as learning aids. At a deeper level they may acquire some technical knowledge to modify programmes. At a third level they may master computers sufficiently to become authors or lesson designers and programmers to create their own courseware from scratch.

The multiplicity of the teachers' roles complicates professional language training (Higgins, 1988:57). Training involves more than giving a set of techniques to teachers; they must also be trained to evaluate and determine whether a teaching technique is good or not. These decision-making skills also with regard to CALI can best be learned by putting teachers in the roles of students.

\section{Suggested outline of a teachers' training course}

The ideas suggested below should not be seen as the "full and final" picture of this type of training. They are intended to be general guidelines.

6.1 History: A good place to start will be the history of teaching machines and computers from the 17th century until today. Teachers should note that Lord Byron's daughter programmed on one of the earliest teaching machines and that one of the present programming languages, ADA, was named after her! The computer is a relatively new tool in arts and letters and should not be seen as something with which every teacher is familiar. The best we can hope for at the moment is a "demystification for computers" (Higgins, 1988:60); a removal of the fear of computers. 
6.2 CALI terminology: New vocabulary in any second or foreign language must be learned and seems to be useful. The same applies to CALI terminology. These terms should be presented to teachers as stepping stones so that they can make more progress. Recent glossaries of computer terms can be very useful in this regard.

6.3 Programming languages: Personally I am not very much in favour of teachers learning to programme as well. However, if a teacher is interested in doing it, a training course should make provision for it, even if it is an optional extra in the training program.

Perhaps one should spend some time on the question whether language teachers should become programmers. Computer training is often regarded as training in the BASIC computer language (Higgins, 1988:60-61). During such a course different computer languages are given different ratings according to their suitability for language teaching applications.

To bring more clarity to this question, let us consider traditional classroom teaching for a moment. Very few teachers become textbook writers, but as users they quickly learn whether a textbook is useful or not. By the same token one could say that very few teachers will become real programmers. There may be a few who have a special talent and can become expert software writers. There is a real need for such persons!

On the other hand, one could argue that teachers should learn to programme for it allows them to grapple with a problem-solving approach to language teaching. Before one can get a computer to display or to process language, one has to look at it from the computer's point of view - i.e. in a cold logical way. You have, in a sense, to teach the dumb computer to do something and in that way you will learn something yourself.

As you can see from the above-mentioned discussion, there is no cut and dry answers to the question as to whether language teachers should also learn to programme a computer. In the end it boils down to this: if you have the talent and interest, do it; if you don't, let somebody else do it!

It will be impossible to indicate which programming language should be introduced in a course but one should caution that BASIC is not as basic as the name may lead you to believe; neither is QuickBASIC as quick to learn as the name might suggest! 
6.4 Hardware: It might be useful to introduce teachers to more than one type of computer. In the South African context they may be faced with Commodore, Apple, BBC, TOAN, or IBM compatible computers. It is beneficial for a teacher to know that there is a difference in the loading procedure for an IBM microcomputer. Although a teacher may not have to learn to programme, it is essential that knowledge of the Disk Operating System for a particular computer is acquired. It is taken for granted that teachers will know that a program which runs on an Apple will not run on an IBM, one of the reasons being a different operating system.

6.5 Strategies for teacher training: As far as the strategies are concerned, one should look at more detail (Jones and Fortescue, 1987:128-131).

6.5.1 Aims: The training should bolster the teachers' confidence to operate the computer. It should make them aware of programmes that are available and whether these programmes are worthwhile. It should encourage them to see the computer as an aid rather than a rival. The training should also make them think creatively about the way in which a programme can be used.

6.5.2 Strategies: These will depend on: the circumstances of individual schools; the time available for training; the age, attitude, and abilities of the teachers involved. The main strategy should be to make the sessions practical rather than theoretical.

One of the main components of computer-phobia is fear of the keyboard. It therefore makes sense to begin the training with a programme which does not rely heavily on keyboarding, but which uses the arrow (direction) keys.

It is also important to choose for the first session a programme which has clear educational objectives, which will load without problems, and which has crystal-clear instructions. It should be remembered that also in this case first impressions are vitally important.

It may be a good idea to let teachers work through the first programme in groups. After they have done this, the group could meet to share their views and experiences.

If the first programme could have an authoring component, it will be beneficial. This does not mean that teachers should use the authoring section during the first session. In later sessions this 
programme could be a good point of reference when they do have to start authoring material. By mentioning the authoring section, teachers can start thinking about possible ways to enhance the programme for their own purposes.

The trainer should emphasize that teachers will not use a large range of programmes in the beginning. Fairly low objectives should be set. Teachers should understand that, as time goes by, their knowledge about programmes will improve.

It would be worthwhile if similar types of programmes could be made available to teachers so that they can practise during follow-up sessions. Keeping copyright restrictions in mind, it is perhaps better not to give programmes out so that the teachers could take them home. By organising further workshops teachers can be given the opportunity to view other programmes as well.

6.5.3 Further hints: One should always work from the classroom to the computer and not vice versa. Teachers should be given the opportunity to decide, based on what the class requirements are, what they want to do in the computer sessions.

One should keep teachers away from computer manuals as well as from the inside of computers. It is not necessary to teach them anything about the working of a computer unless they very specifically ask about it.

One last hint would be to make computer magazines and journals freely available to teachers. In the present situation it may be very expensive to make more than one magazine available because of the high cost. One way around this problem could be to borrow computer magazines from a nearby university library or computer shop. Joint subscription to a magazine could also be considered.

\section{Conclusion}

Given enough time as well as systematic training, the majority of teachers and students will use computers. Not all of them will become equally proficient but this is not what it is about. The important thing is that they are using computers. What is also important is that no teacher should be deterred from experimenting with computers by fears of "technology inadequacy" (Jones and Fortescue, 1987:131).

It can be assumed that experimentation will breed familiarity! 


\section{Bibliography}

ATTISHA, M., and M. Yazdani. 1984. An expert system for diagnosing children's multiplication errors. Instructional Science 13.

CURTIN, C.O., and S.L. SHINAL. 1987. Teachers' training for CALI and its implications. In: $\quad$ SMITH, F.W. (Ed.). Modern media in foreign language education. Lincolnwood: National Textbook Company.

HEALEY, D. Technology, language learning and the future. C.A.L.L. Digest. 3(2), 1988:2-3.

HIGGINS, J. 1988. Language, learners and computers. London: Longman.

HIGGINS, J. and T. Johns. 1984. Computers in language learning. London: Collins ELT.

JONES, C. and S. Fortescue. 1987. Using computers in the language classroom. London: Longman.

LEONARD, J. 1985. Computers in language and literacy work. London: Adult Literacy and Basic Skills Unit (ALBSU).

ROBERTSON, B. The future of CD-ROM. Computer Graphics World. June 1988:53-58.

UNDERWOOD, J.H. 1984. Linguistics, computers, and the language teacher. Rowley: Newbury House.

YAZDANI, M. 1986. The ideal teaching machine. In: Cameron, K.C., W.S. Dodd and S.P.O. Rahtz, (Eds.). Computers in modern language studies. Chicester: Ellis Horwood.

\section{List of acronyms and abbreviations used in text}

BETHA, VHS Two incompatible video tape standards used over the world

CAL Computer-Assisted Learning

CALI Computer-Assisted Language Instruction

CD-I Compact Disc Interactive

CD-ROM Compact Disc - Read Only Memory

DVI Digital Video Interactive 
MS-DOS Disk Operating System (Microsoft Corporation)

NTSC American Television Standard

PAL European (and South African) Television Standard

QUEST Authoring System for creating (authoring) lesson material

QWERTY Name for standard typewriter or computer keyboard - refers to 5 adjacent keys

SECAM French Television Standard

VCR Video Cassette Recorder

WORM Write Once, Read Many times 